\title{
Technical exploration of horizontal screw centrifuge in solid-liquid separation of flowback liquid in offshore production
}

\author{
Su Hui ${ }^{1}$, HE Ya-qi ${ }^{2}$, ZHAO Yu ${ }^{2}$, SUN Chao ${ }^{2}$, MA Jun ${ }^{2}$, Xia Hong-ze ${ }^{2}$, MA Wen-jie $^{*}$, Sun Pei ${ }^{1}$ \\ ${ }^{1}$ CNOOC Energy Technology \& Services Limited, Safety \& Environmental Protection Branch 300452, China; \\ ${ }^{2}$ Tianjin Branch Co.,CNOOC Ltd.,Tianjin, Tianjin 300452, China
}

\begin{abstract}
This paper introduces the structure and working principle of horizontal screw centrifuge with large length diameter ratio and its technological process in the separation of liquid-solid liquid in the flowback of offshore production. The effects of different water addition ratio, rotating speed and demulsifier content on the separation effect of centrifuge were investigated by indoor experiments. The orthogonal test was used to optimize the parameters, and the optimal combination of parameters was as follows: water ratio was $1.5 / 1$, rotating speed was 3000r/min, demulsification was achieved The dosage was $400 \mathrm{mg} / \mathrm{L}$. The optimum rotating speed of the centrifuge is $2000 \mathrm{r} / \mathrm{min}$, and the field pilot test is carried out for 10 consecutive days with the best combination of parameters. The results are as follows: the average mechanical impurity rate of oil phase produced by horizontal screw centrifuge is $0.465 \%$, and the average oil content in water phase is $183 \mathrm{mg} / \mathrm{L}$. The separation effect is stable.
\end{abstract}

\section{Introduction}

As offshore oilfield production increases, the volume of flowback liquid generated in oil and water treatment systems on offshore platforms has surged. These flowback liquid are primarily stored in slop tanks/closed discharge tanks and wastewater tanks, and then pumped into the oil and water treatment process ${ }^{1}$. The impurities in the flowback liquid mainly include suspended solid, waxes, colloids, bacteria, corrosion products, and polymeric agents, which are characterized by high solids content, high viscosity, high oil content, and high emulsion stability ${ }^{2}$. Therefore, the solid-phase impurities would infinitely circulate in the oil and water treatment systems. Resulting from this, the mechanical impurity content in the oil treatment system would increase. Also, the oil content and the equipment failure rate in the water treatment system would rise and the burden on the wastewater treatment system and the cost of pharmaceuticals would build up ${ }^{3-4}$. The current solution is to open the offshore closed-loop oil and water circulating treatment system at a specific point so that the solid-phase impurities in the system can be separated. In doing so, the "waste" in the oil and water system can be gradually cleared out through "dialysis", and then the "purification" of the oil and water treatment system can be achieved. However, due to the limitations of the offshore platform conditions, how to achieve a high-efficiency and maximum "dialysis" of the "waste" is an urgent problem to be solved.

With the continuous development of related technologies at home and abroad, horizontal screw centrifuge is widely used in oil exploration and other industries. Compared with other separation machinery (such as filter press, filtration equipment), horizontal screw centrifuge has many advantages, such as small size, small infrastructure investment, a high degree of automation, simple operation, no secondary pollution ${ }^{5}$. Therefore, the centrifuge is more suitable for solid-liquid separation of the flowback liquid in the offshore platform. Research shows that different water addition ratio and demulsifier content have different effects on the separation effect. Meanwhile, the parameters of horizontal screw centrifuge, such as separation factor (rotational speed), length-to-diameter ratio, also affect the separation effect. Therefore, this paper investigates the effects of different water addition ratio, demulsifier content, and separation factor (rotational speed) on the separation effect through indoor experiments. Through the orthogonal test, the parameters are optimized and the optimum combination of the three parameters is obtained, which are then testified by means of the field pilot test.

\section{Materials and Methods}

\subsection{Materials}

\subsubsection{Source and Physical Property Analysis of Flowback Liquid}

The flowback liquid in offshore production is produced from oilfield platform operations, mainly including the backwashing of swashplate, air-float oil recovery, and 
walnut shell filtration, the collection operation of open and closed discharge systems, and the clearing of the sludge from the bottom of the tank, and high content, severe emulsification, and high separation difficulty of mechanical impurities. The specific source is shown in Figure 1. The main physical properties are shown in Table 1

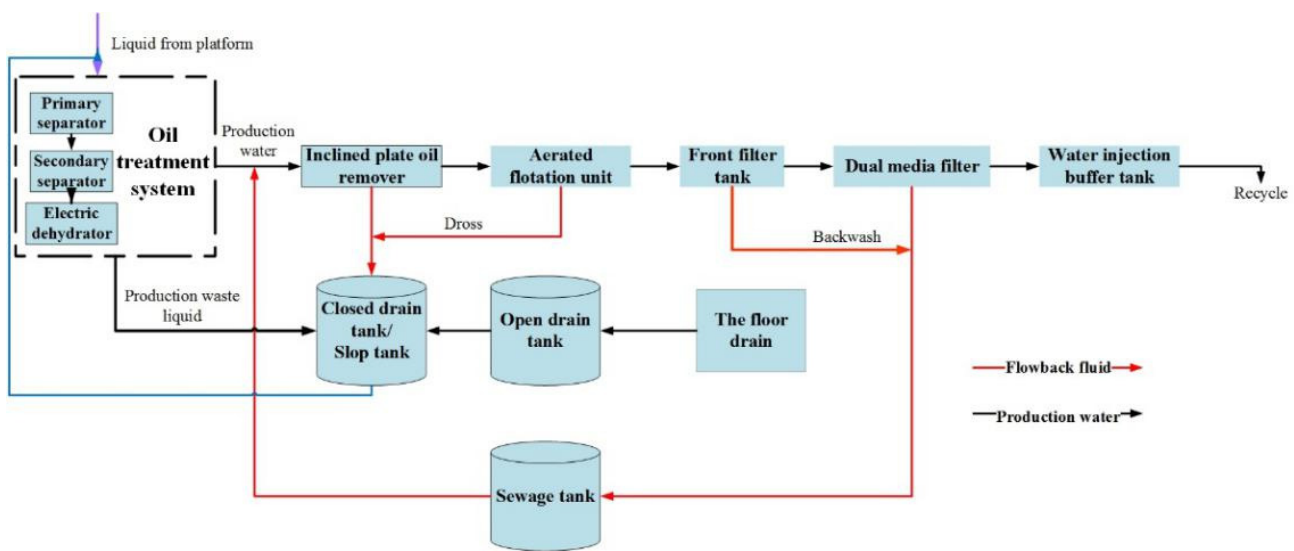

Fig. 1 Source of flowback fluid

Table 1 Physical Property Analysis of flowback fluid

\begin{tabular}{cccc}
\hline Parameter & $\begin{array}{c}\text { Soild } \\
\text { content }(\%)\end{array}$ & $\begin{array}{c}\text { Water content } \\
(\%)\end{array}$ & $\begin{array}{c}\text { Oil } \\
\text { content } \\
(\%)\end{array}$ \\
\hline Percentage & 11.43 & 77.31 & 11.26 \\
\hline
\end{tabular}

\subsubsection{Experimental Materials and Instruments}

The flowback liquid used in the experiment is from an offshore oilfield platform. Other materials: carbon tetrachloride, sodium chloride, anhydrous sodium sulfate, gasoline, demulsifier (BP-03), distilled water, and so on.

German Sigma-6 benchtop low-speed centrifuge, infrared oil detector, constant temperature water bath, oscillator, analytical balance, electric constant temperature drying oven, distribution funnel, filter paper, and so on.

\subsection{Methods}

\subsubsection{Structure and Working Principle of Horizontal Screw Centrifuge}

The horizontal screw centrifuge mainly consists of a rotary drum, screw pusher, drive device, and protection device $^{6}$. The flowback liquid arrives at the rotary drum through the screw pusher. Due to the speed difference, the lighter liquid will be developed into a liquid loop in the rotary drum and then discharged from the overflow drain, while the heavier solids will settle down on the walls of the rotary drum under the effect of the centrifugal force and then be thrown out of the equipment through the residue drain outlet ${ }^{7-8}$. The structure of the horizontal screw centrifuge is shown in Figure 2.

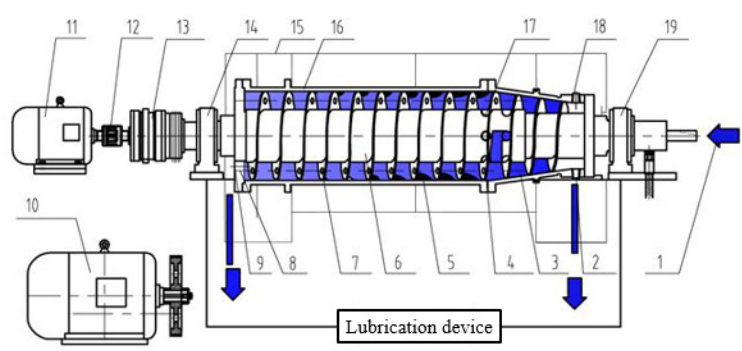

1: feed port; 2 : slag outlet; 3 : cone-end dehydration area; 4: inlaid welded carbide plate; 5 : straight section settlement area; 6 : screw propeller; 7: clear liquid guide hole; 8: liquid outlet; 9: adjusting plate; 10: main motor; 11: auxiliary motor; 12: elastic coupling; 13: differential; 14: bearing seat; 15: cover; 16: drum; 17: wear-resistant sleeve at discharge port; 18: wear-resistant sleeve at slag outlet; 19: bearing seat

Fig. 2 Structure of high efficiency horizontal screw centrifuge

\subsubsection{Process Flow}

Pump the flowback liquid generated from the oil field into the homogenization tank, and add water and demulsifier to precipitate and buffer, and then pump them into the horizontal screw centrifuge through the input pump for treatment. The liquid discharged from the liquid drain outlet of the centrifuge is an oil-water mixture, which needs to be sent into the liquid-phase treatment system for further treatment. The solids discharged from the residue drain outlet of the centrifuge is recycled into the rock chip box or sludge tank, and then transported back to the terminal treatment plant for treatment, as shown in Figure 3.

The mechanical impurity rate in the oil phase is tested 
according to GB/T 511-1988 Petroleum products and additives-Determination of mechanical impurities-Gravimetric method ${ }^{9}$. The oil content in the

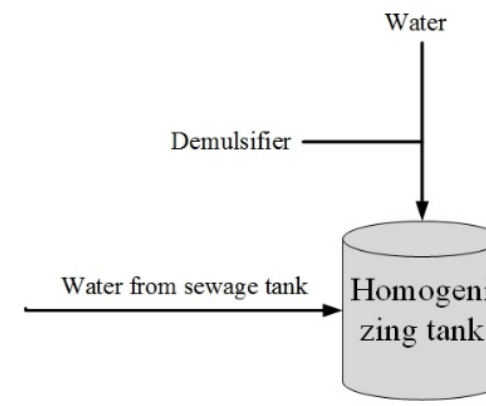

\subsubsection{Experimental Design}

Fix the rotational speed of the centrifuge at $2500 \mathrm{r} / \mathrm{min}$, fix the demulsifier content at $500 \mathrm{mg} / \mathrm{L}$, and then adjust the water addition ratio. Fix the water addition ratio at $1 / 1$, fix the demulsifier content at $500 \mathrm{mg} / \mathrm{L}$, and then adjust the rotational speed of the centrifuge. Fix the water water phase is tested according to HJ 637-2012 Water quality-Determination of petroleum oils and animal and vegetable oils-Infrared spectrophotometry ${ }^{10}$.

Table 2 Gradient setting table

\begin{tabular}{cccccccc}
\hline Water addition ratio & $1 / 4$ & $1 / 3$ & $1 / 2$ & $1 / 1$ & $1.5 / 1$ & $2 / 1$ & - \\
Rotational speed $(\mathrm{r} / \mathrm{min})$ & 1000 & 1500 & 2000 & 2500 & 3000 & 3500 & 4000 \\
Demulsifier content $(\mathrm{mg} / \mathrm{L})$ & 200 & 300 & 400 & 500 & 600 & 700 & 800 \\
\hline
\end{tabular}

\section{Results}

\subsection{Result of Indoor Experiments}

\subsubsection{Analysis of Single-Factor Test Results}

(1) The effect of different water addition ratios on the separation effect of centrifuge

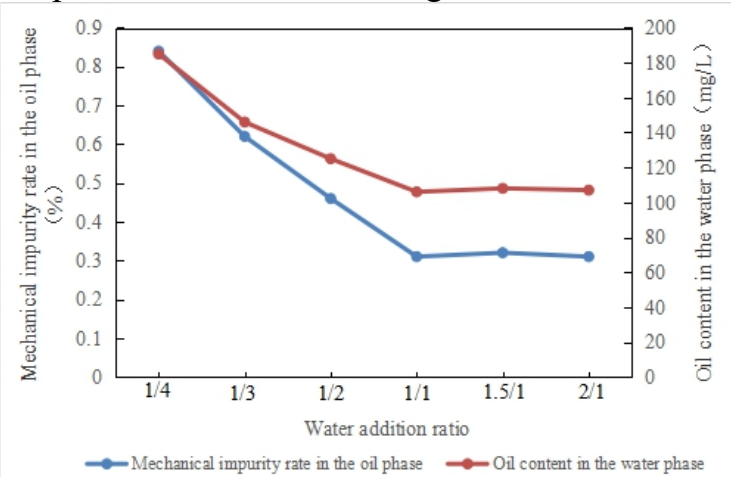

Fig. 4 Effect of different addition ratio on separation effect

As we can see from Figure 4, when the rotational speed and demulsifier content of the centrifuge are fixed, with the increase of water addition ratio, the mechanical impurity rate in the oil phase and the oil content in the addition ratio at $1 / 1$, fix the rotational speed of the centrifuge at $2500 \mathrm{r} / \mathrm{min}$, and then adjust the demulsifier content. The specific gradient setting is shown in Table 2. According to the results of the single-factor test, the orthogonal test is used to optimize the parameters. In this way, the optimum rotational speed, water addition ratio, and demulsifier content can be obtained.

water phase would first decline and then remain stable. The turning point of both appears when the water addition ratio of $1 / 1$. At this time, the mechanical impurity rate in the oil phase is $0.31 \%$ and the oil content in the water phase is $106 \mathrm{mg} / \mathrm{L}$.

(2) The effect of different rotational speeds on the separation effect of centrifuge

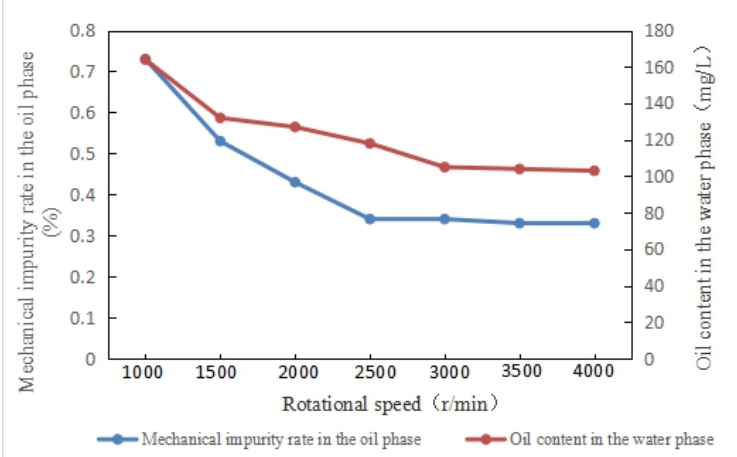

Fig. 5 Effect of different rotating speed on separation effect

As we can see from Figure 5, when the water addition ratio and demulsifier content are fixed, with the increase of rotational speed, the mechanical impurity rate in the oil phase and the oil content in the water phase tend to decrease first and then stabilize. The mechanical impurity rate stabilizes at 0.34 when the rotational speed is $2500 \mathrm{r} / \mathrm{min}$, while the oil content stabilizes at $105 \mathrm{mg} / \mathrm{L}$ when the rotational speed is $3000 \mathrm{r} / \mathrm{min}$. 
(3) The effect of the demulsifier content on the separation effect of centrifuge

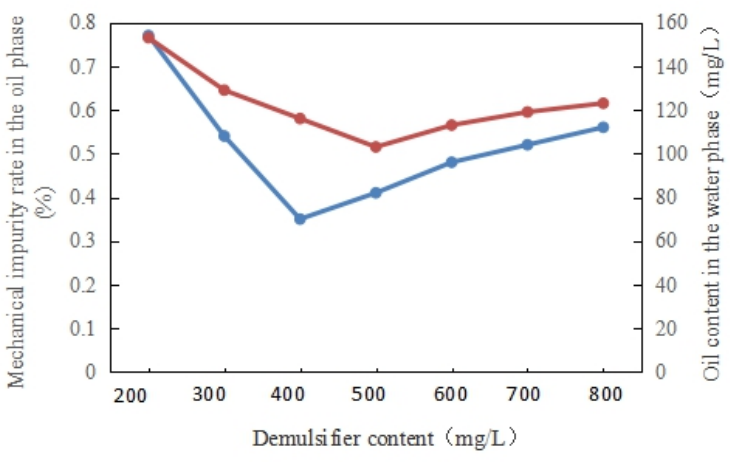

Fig. 6 Effect of different demulsifier content on separation efficiency

As we can see from Figure 6, when the water addition ratio and the rotational speed are fixed, with the increase of the demulsifier content, the mechanical impurity rate in the oil phase tends to increase and then decrease, and the lowest point is $0.35 \%$ when the demulsifier content is $400 \mathrm{mg} / \mathrm{L}$; the oil content in the water phase also tends to increase and then decrease, and the lowest point is
$103 \mathrm{mg} / \mathrm{L}$ when the demulsifier content is $500 \mathrm{mg} / \mathrm{L}$.

\subsubsection{Analysis of Orthogonal Test Results}

Through the analysis of the single-factor test result, it is found that three factors, namely, the water addition ratio, the rotational speed, and the demulsifier content, have a great influence on the separation effect of the centrifuge. Therefore, this study aims to use the orthogonal test method to optimize the process. The orthogonal test factor level table, test result table, and range calculation table are separately shown in Table 3, Table 4, and Table 5. As we can see from the range calculation table, the optimum combination of the mechanical impurity rate in the oil phase is $\mathrm{A} 2 \mathrm{~B} 3 \mathrm{Cl}$. Due to $\mathrm{RC}>\mathrm{RA}>\mathrm{RB}$, the demulsifier content affects the mechanical impurity rate in the oil phase the most. The optimum combination of the oil content in the water phase is $\mathrm{A} 2 \mathrm{~B} 3 \mathrm{C} 2$ or $\mathrm{A} 2 \mathrm{~B} 3 \mathrm{C} 3$. Due to $R B>R A>R C$, the demulsifier content has the third greatest effect on the oil content in the water phase. Therefore, the optimum combination is $\mathrm{A} 2 \mathrm{~B} 3 \mathrm{C} 1$, that is, the water addition ratio is $1.5 / 1$, the rotational speed is $3000 \mathrm{r} / \mathrm{min}$, and the demulsifier content is $400 \mathrm{mg} / \mathrm{L}$.

Table 3 Orthogonal test factor level table

\begin{tabular}{cccc}
\hline \multirow{2}{*}{ Level } & Factor A & Factor B & Factor C \\
\cline { 2 - 4 } & Water addition ratio & Rotational speed $(\mathrm{r} / \mathrm{min})$ & Demulsifier content $(\mathrm{mg} / \mathrm{L})$ \\
\hline 1 & $1 / 1.0$ & 2000 & 400 \\
2 & $1 / 1.5$ & 2500 & 500 \\
3 & $1 / 1.2$ & 3000 & 600 \\
\hline
\end{tabular}

Table 4 Orthogonal test scheme and result table

\begin{tabular}{|c|c|c|c|c|c|}
\hline \multirow{2}{*}{ Test No. } & \multicolumn{3}{|c|}{ Factor } & \multirow{2}{*}{$\begin{array}{l}\text { Mechanical impurity } \\
\text { rate in the oil phase }(\%)\end{array}$} & \multirow{2}{*}{$\begin{array}{l}\text { Oil content in the water } \\
\text { phase }(\mathrm{mg} / \mathrm{L})\end{array}$} \\
\hline & $\mathrm{A}$ & $\mathrm{B}$ & $\mathrm{C}$ & & \\
\hline 1 & 1 & 1 & 1 & 0.38 & 109.00 \\
\hline 2 & 1 & 2 & 2 & 0.42 & 112.00 \\
\hline 3 & 1 & 3 & 3 & 0.37 & 103.00 \\
\hline 4 & 2 & 1 & 2 & 0.41 & 104.00 \\
\hline 5 & 2 & 2 & 3 & 0.35 & 111.00 \\
\hline 6 & 2 & 3 & 1 & 0.32 & 105.00 \\
\hline 7 & 3 & 1 & 3 & 0.44 & 108.00 \\
\hline 8 & 3 & 2 & 1 & 0.36 & 110.00 \\
\hline 9 & 3 & 3 & 2 & 0.43 & 106.00 \\
\hline
\end{tabular}

Table 5 Range calculation of each evaluation index

\begin{tabular}{ccccc}
\hline & Variable & \multicolumn{3}{c}{ Factor } \\
\cline { 3 - 5 } & & $\mathrm{A}$ & $\mathrm{B}$ & $\mathrm{C}$ \\
\hline \multirow{2}{*}{$\begin{array}{c}\text { Mechanical impurity rate in } \\
\text { the oil phase }\end{array}$} & $\mathrm{k} 2$ & 0.39 & 0.41 & 0.35 \\
& $\mathrm{k} 3$ & 0.36 & 0.38 & 0.42 \\
\end{tabular}




\begin{tabular}{|c|c|c|c|c|}
\hline & $\mathrm{R}$ & 0.05 & 0.04 & 0.07 \\
\hline \multirow{4}{*}{$\begin{array}{l}\text { Oil content in the water } \\
\text { phase }\end{array}$} & $\mathrm{k} 1$ & 108.00 & 107.00 & 108.00 \\
\hline & $\mathrm{k} 2$ & 106.67 & 111.00 & 107.33 \\
\hline & $\mathrm{k} 3$ & 108.00 & 104.67 & 107.33 \\
\hline & $\mathrm{R}$ & 1.33 & 6.33 & 0.67 \\
\hline
\end{tabular}

\subsection{Results of Field Pilot Test}

\subsubsection{Determination of Rotational Speed of Horizontal Screw Centrifuge}

The above orthogonal test shows that the optimum rotational speed is $3500 \mathrm{r} / \mathrm{m}$, which corresponds to the separation factor of 1007.1 . In the field pilot test, it should also be ensured that the separation factor of horizontal screw centrifuge is 1007.1. Based on the relationship between the separation factor and rotational speed, it can be calculated that the rotational speed of the horizontal screw centrifuge shall remain at 2000r/min.

\subsubsection{Test Design}

The horizontal screw centrifuge with a large length-to-diameter ratio is used in the field. According to the above orthogonal test result, the optimum water addition ratio and demulsifier content are 1.5/1 and $400 \mathrm{mg} / \mathrm{L}$ respectively. Keep the rotational speed at about $2000 \mathrm{r} / \mathrm{min}$. Then conduct the pilot test for 10 consecutive days.

\subsubsection{Test Results}

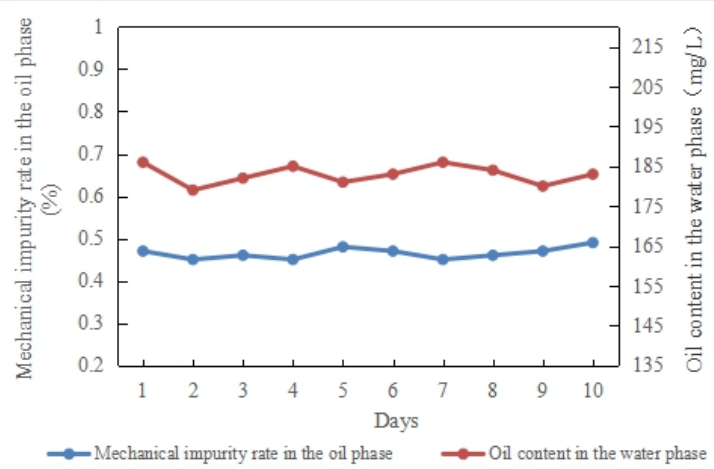

Fig. 7 Analysis of field pilot test results

As we handled $40 \mathrm{~m} 3$ of flowback liquid with an efficiency of $0.5 \mathrm{~m} 3 / \mathrm{h}$ for ten consecutive days and worked $8 \mathrm{~h}$ per day, the average mechanical impurity rate in the oil phase of the horizontal screw centrifuge contained is $0.465 \%$, and the average oil content in the water phase is $183 \mathrm{mg} / \mathrm{L}$. The operation was in good condition and the separation effect was stable.

\section{Conclusion}

(1) When all other conditions are held constant, the mechanical impurity rate in the oil phase and the oil content in the water phase are 0.31 and $106 \mathrm{mg} / \mathrm{L}$ respectively when the water addition ratio is greater than $1 / 1$. When all other conditions are held constant, the lowest mechanical impurity rate is $0.34 \%$ at the rotational speed of $2500 \mathrm{r} / \mathrm{min}$, and the lowest oil content is $105 \mathrm{mg} / \mathrm{L}$ at the rotational speed of $3000 \mathrm{r} / \mathrm{min}$. When all other conditions are held constant, the lowest mechanical impurity rate is $0.35 \%$ at the demulsifier content of $400 \mathrm{mg} / \mathrm{L}$, while the lowest oil content is $103 \mathrm{mg} / \mathrm{L}$ at the demulsifier content of $500 \mathrm{mg} / \mathrm{L}$.

(2) Combination of parameters for the optimum separation effect in the indoor experiment: the water addition ratio is $1.5 / 1$, the rotational speed is $3000 \mathrm{r} / \mathrm{min}$, and the demulsifier content is $400 \mathrm{mg} / \mathrm{L}$.

(3) Results of the field pilot test: The average mechanical impurity rate in the oil phase of the horizontal screw centrifuge is $0.465 \%$. The average oil content in the water phase is $183 \mathrm{mg} / \mathrm{L}$. The separation effect is stable, which can meet the requirements of solid-liquid separation of the flowback liquid in offshore production.

\section{Acknowledgements}

* Fund projects: Major National Science and technology projects (2016ZX05058-003-014)

This work was supported by the major national science and technology projects of China (No. 2016ZX05058-003-014)

\section{Reference}

1. Y G Liu, L P Huang, B Huang, et al. Treatment technology of acidizing flowback fluid in offshore oilfield [J]. Fine and specialty chemicals, 2020, 28(01): 25-29.

2. T Gao, W H Wang, T Wang, et al. Research and application of oilfield flowback fluid treatment technology $[\mathrm{J}]$. Petrochemical application, 2016, 35(11): 72-75.

3. J P Liu. Design and application of desanding device for oil well flowback fluid [D]. Xi'an Shiyou University, 2017.

4. D Y Kang, C Xue, C T Qu, et al. Reinjection treatment and feasibility evaluation of fracturing flowback fluid [J]. Chemical engineering, 2019, 47(07): 5-9.

5. D C Wang. Operation optimization of horizontal screw centrifugal dehydrator in oily sludge 
dewatering [D]. Xi'an Technological University, 2013.

6. Z G Liu, X D Dai. Application of z4e-3/951 horizontal screw centrifuge in oily sludge treatment of Suizhong 36-1 crude oil treatment plant [J]. Tianjin Chemical, 2015, 29(05): 32-34.

7. C X Liu, L Fu, T Jing. Experimental study on dewatering of oily sludge in horizontal screw centrifuge [J]. Filtration and separation, 2004(02): 28-31.

8. X He. Study on selection factors of horizontal screw centrifuge [J]. Water supply and drainage, 2010, 46(10): 94-99.

9. GB T 511-1988 petroleum products and additives determination of mechanical impurities (Gravimetric method) [S]

10. HJ637-2012 water quality determination of petroleum and animal oils (Infrared spectrophotometry) [S] 